\title{
Massive underreporting of type II Diabetes in emergency department admissions
}

\author{
Josefin Gustafsson*, Søren Wistisen Rasmussen, Thomas Schmidt-Andersen \\ From Proceedings of the 5th Danish Emergency Medicine Conference \\ Aarhus, Denmark. 18-19 April 2013
}

\section{Background}

The prevalence of type 2 diabetes mellitus (T2DM) has continued to increase in developed and developing countries in past decades. T2DM is the most frequent chronic disease in Denmark with a prevalence of $4 \%$, with an equal estimated prevalence of undiagnosed cases. T2DM is associated with several complications that can lead to acute deterioration and need of acute admittance to the hospital. Every day 10 patients die from T2DM-related complications in Denmark. The objectives of this study were: 1 ) to establish the number of patients with T2DM referred to the Department of Internal Medicine via the Emergency Department and the number of patients who were diagnosed with T2DM upon referral; 2) to report which anti-diabetics they used at the time of admittance.

\section{Methods}

A chart review during a 1 year period was conducted, i.e. from 01-JUL-2011 to 30-JUN-2012 looking at all registered cases of T2DM including both primary and secondary diagnosis.

\section{Results}

The Emergency Department yearly admits and refers around 18,000 internal medicine patients. A total of only 31 cases with T2DM were captured. Twenty-eight were known to have T2DM and three were diagnosed with the disease at admittance. Oral anti-diabetics had been prescribed to $67 \%$ of patients, oral anti-diabetics in combination with either GLP-1 agonist or insulin to $17 \%$, leaving $13 \%$ of the patients with insulin.

* Correspondence: jal.gustafsson@gmail.com

The Emergency Department, Holbaek University Hospital, Denmark

\section{Conclusion}

With a T2DM prevalence of $4 \%$, the expected number of admissions was 720 patients. This indicates an underreporting of T2DM of approximately $96 \%$, which probably results from registration of complications related to $\mathrm{T} 2 \mathrm{DM}$ and not the underlying disease itself. Because T2DM is regarded as a global epidemic, registration of patients with T2DM needs to be improved so that the quality of both primary and secondary care can be ensured. Because of underreporting the reported antidiabetic treatment is unlikely to be representative.

Published: 9 September 2013

doi:10.1186/1757-7241-21-S2-A35

Cite this article as: Gustafsson et al:: Massive underreporting of type II Diabetes in emergency department admissions. Scandinavian Journal of Trauma, Resuscitation and Emergency Medicine 2013 21(Suppl 2):A35.

\section{Submit your next manuscript to BioMed Central and take full advantage of: \\ - Convenient online submission \\ - Thorough peer review \\ - No space constraints or color figure charges \\ - Immediate publication on acceptance \\ - Inclusion in PubMed, CAS, Scopus and Google Scholar \\ - Research which is freely available for redistribution

